\title{
Serodiagnostic Efficacy of Mycobacterium tuberculosis 30/32-kDa Mycolyl Transferase Complex, ESAT-6, and CFP-10 in Patients with Active Tuberculosis
}

\author{
Gavish Kumar • Pradeep Kumar Dagur • Prashant Kumar Singh • \\ Hari Shankar • Virendra S. Yadav • Vishwa M. Katoch • Bharat Bajaj • \\ Rajesh Gupta $\cdot$ Utpal Sengupta $\cdot$ Beenu Joshi
}

Received: 29 January 2009/ Accepted: 2 June 2009/Published online: 5 January 2010

(C) L. Hirszfeld Institute of Immunology and Experimental Therapy, Wroclaw, Poland 2010

\begin{abstract}
Elimination of tuberculosis (TB) largely depends upon definitive rapid diagnosis and treatment. Widely used diagnostic tests do not qualify for use in a developing country due to lack of either desired accuracy or their cost. In the present study an enzyme-linked immunosorbent assay was used to evaluate the diagnostic potential of an immuno-dominant 30/32-kDa mycolyl transferase complex (Ag85 complex) and Mycobacterium tuberculosis-specific proteins (ESAT-6 and CFP-10) of the RD1 region. Higher sensitivity (84.1\%) with Ag85 complex was observed compared with ESAT-6 (64.9\%) and CFP-10 (66\%), with almost similar specificity (Ag85: 85.2\%, ESAT-6: $88.9 \%$, CFP-10: $85.2 \%$ ), whereas the individual components of Ag85 complex, i.e. Ag85A, $\mathrm{Ag} 85 \mathrm{~B}$, and $\mathrm{Ag} 85 \mathrm{C}$, showed sensitivities of $44.6,34$, and $80.9 \%$ and specificities of 55.6, 74.1, and $40.7 \%$ respectively. A cocktail of Ag85 complex, ESAT-6, CFP-10, $\mathrm{Ag} 85 \mathrm{~A}, \mathrm{Ag} 85 \mathrm{~B}$, and Ag85C antigens also could not help in increasing either sensitivity (51.1\%) or specificity (85.2\%). Furthermore, immunoblot analysis using clinical isolates as well as a standard strain (H37Rv) of M. tuberculosis also showed strong reactivity of sera from TB patients to Ag85 complex and, to a lesser extent, also to ESAT-6. To
\end{abstract}

G. Kumar · P. K. Dagur · P. K. Singh · H. Shankar ·

V. S. Yadav · V. M. Katoch · U. Sengupta - B. Joshi $(\bowtie)$

National JALMA Institute for Leprosy and Other Mycobacterial

Diseases (ICMR), Taj Ganj, Agra 282001, India

e-mail: bjjalma@gmail.com; beenuj2002@yahoo.co.in

B. Bajaj

State TB Demonstration Centre,

S. N. Medical College, Agra 282002, India

R. Gupta

Department of TB and Chest Diseases,

S. N. Medical College, Agra 282002, India conclude, use of Ag85 complex along with ESAT-6 and CFP-10 seems to be promising in minimizing the heterogeneous sero-responses of adult TB cases.

Keywords Secretory proteins .

30/32-kDa Mycolyl transferase complex .

ESAT-6/CFP-10 - Serodiagnosis · Tuberculosis

\section{Introduction}

Tuberculosis (TB) is a growing health problem in the developing world. Nine million new cases of TB and three million deaths are reported every year around the globe (WHO 2007). In asymptomatic individuals, TB infection can be diagnosed with the help of the intra-dermal skin test using purified protein derivative (PPD). It is impossible to distinguish between present and past infection on the basis of a PPD test and this test is also not specific in BCGvaccinated individuals (Huebner et al. 1993). Furthermore, conversion of the PPD reactivity from negative to positive challenges the clinician (Fine et al. 1999).

The specificity of acid-fast bacilli (AFB) staining is typically $>99 \%$ and the sensitivity of this test varies between 25 and 75\% (American Thoracic Society 2000). A positive AFB test and negative culture result may be caused by nonviable bacilli, when a person is receiving anti-TB drugs. The culture technique has an advantage in distinguishing the morphology of Mycobacterium tuberculosis from those of some non-tuberculous mycobacteria. However, it requires more time for results (3-4 weeks) (Thornton et al. 1998). Advanced molecular techniques such as PCR and BACTEC are, although rapid, sensitive, and specific (Hawkinds et al. 1991; Noordhoek et al. 1994), are not available everywhere and are also not cost effective. 
Active pulmonary TB is contagious and leads to the spread of $M$. tuberculosis. Therefore, rapid and early diagnosis is needed for a TB control program. Various studies have been undertaken to develop a serodiagnostic test using secretory proteins of $M$. tuberculosis as these are known as immuno-dominant and early markers for TB (Kanaujia et al. 2003; Malen et al. 2008; Samanich et al. 2000). Among these proteins, ESAT-6 (Rv3875) and CFP10 (Rv3874) are known as $M$. tuberculosis-specific antigens as they are absent in BCG and in most of the nonpathogenic mycobacteria (Arend et al. 2000; Harboe et al. 1996); therefore these antigens could differentiate infected and BCG-vaccinated individuals with TB. The role of these antigens in the early diagnosis and latent TB was previously reported (Silva et al. 2003). A well-defined fraction of the secretory proteins is Ag85 complex (30/32$\mathrm{kDa}$ mycolyl transferases) abundantly found in culture filtrate of M. tuberculosis (Wiker and Harboe 1992). This is a family of three closely related proteins (Ag85A, Ag85B, and Ag85C) found in all mycobacteria (Wiker et al. 1986). Ag85 complex was recently reported to be an immunodominant marker for TB (Malen et al. 2008).

In our recent report we showed the potential of $\mathrm{Ag} 85 \mathrm{C}$ in childhood TB cases (Kumar et al. 2008). The present study was conducted to find out the diagnostic potential of immunodominant Ag85 complex as well as its individual components and highly specific (ESAT-6, CFP-10) secretory antigens using enzyme-linked immunosorbent assay (ELISA) for the serodiagnosis of adult TB in a tuberculosis and leprosy endemic country, India. Furthermore, the study was also extended using a cocktail of all these antigens. The reactivity of sera was also evaluated using immunoblot analysis.

\section{Materials and Methods}

\section{Study Subjects}

Serum samples of 86 confirmed active TB patients were obtained from the State Tuberculosis Demonstration
Centre, Agra, and the Department of Tuberculosis and Chest Diseases, S. N. Medical College, Agra. The patients were from the following well-defined categories.

Of the total pulmonary TB cases $(n=76)$, fresh TB cases $(n=48)$ comprised patients who had infection with $M$. tuberculosis bacilli for the first time and had no history of TB treatment. Defaulter TB cases $(n=20)$ comprised TB patients who had not taken the complete course of antitubercular treatment and the symptoms reoccurred. Relapse TB cases $(n=8)$ comprised TB patients who were treated earlier for TB but symptoms reoccurred after completion of the treatment (Table 1). All these patients were examined microbiologically (Ziehl Nielsen staining/ culture) with clinical evaluations. All the pulmonary TB patients were smear positive for AFB. Extra-pulmonary TB patients $(n=10)$ had TB involvement in organs other than the lungs in which the disease was confirmed by tuberculin skin test and suggestive clinical findings (Table 1). The history of tuberculosis contact was available for all the TB patients. Bacteriologically negative, partially or fully treated cases of TB $(n=10)$ were also included in this study. All patients were categorized according to the guideline of the Revised National Tuberculosis Control Program, Central Tuberculosis Division, Government of India.

Healthy controls $(n=29)$ included in this study were staff members or temporary students working in our Institute who had no disease involvement or any family contact history with TB/leprosy patients. Eighteen wellconfirmed leprosy controls (7 lepromatous, 8 borderline tuberculoid, 2 mid-borderline, and 1 tuberculoid leprosy) were also included. These leprosy cases were taken from the outpatient department (OPD) of the National JALMA Institute for Leprosy and Other Mycobacterial Diseases (ICMR), Agra. Two untreated active TB patients, two healthy BCG-vaccinated individuals, and one contact of TB were selected for Western blot analysis on the basis of their antibody response shown in ELISA.

All the patients and controls included in the present study were over 18 and under 65 years of age. Human
Table 1 Details of different groups of patient with tuberculosis and control subjects studied in this study

\begin{tabular}{|c|c|c|c|c|c|}
\hline \multirow[t]{2}{*}{ Study subjects } & \multirow[t]{2}{*}{ Total No. } & \multicolumn{2}{|l|}{ Sex } & \multicolumn{2}{|l|}{ Mean age } \\
\hline & & Male & Female & Year & Range \\
\hline 1. Tuberculosis & 86 & 53 & 33 & & \\
\hline i. Pulmonary cases & 48 & 32 & 16 & $32.6 \pm 13.2$ & $18-65$ \\
\hline ii. Extra-pulmonary cases & 10 & 3 & 7 & $31.0 \pm 14.0$ & $18-65$ \\
\hline iii. Defaulter TB cases & 20 & 10 & 10 & $28.7 \pm 8.8$ & $18-50$ \\
\hline iv. Relapse TB cases & 8 & 8 & 0 & $32.0 \pm 10.8$ & $24-55$ \\
\hline 2. Healthy controls & 29 & 21 & 8 & $25.9 \pm 6.7$ & $22-52$ \\
\hline 3. Leprosy controls & 18 & 12 & 6 & $33.3 \pm 6.8$ & $25-60$ \\
\hline 4. Anti tuberculosis treated cases & 10 & 8 & 2 & $35.3 \pm 12.8$ & $18-58$ \\
\hline
\end{tabular}


immunodeficiency virus (HIV) testing was performed for all the cases and HIV-positive cases were excluded from the study. The study was approved by the institutional ethics committee and informed consent was obtained from each patient.

\section{Antigen and Antibody}

Purified r-ESAT-6, r-CFP-10, native Ag85 complex, its individual components (Ag85A, Ag85B, Ag85C), monoclonal antibody (CS-90) to Ag85 complex, and polyclonal antibody to ESAT-6 and CFP-10 were obtained from Colorado State University (Colorado, USA) through a TB Research Materials and Vaccine Testing Contract (NIH Contract HHSN266200400091C/ADB Contract NOI-AI40091).

\section{Enzyme-Linked Immunosorbent Assay}

One hundred $\mu \mathrm{l}$ of the antigens ESAT-6 (12.5 ng/ml), CFP$10(12.5 \mathrm{ng} / \mathrm{ml})$, Ag85 complex $(12.5 \mathrm{ng} / \mathrm{ml}), \mathrm{Ag} 85 \mathrm{~A}$ (50 ng/ml), Ag85B (6.25 ng/ml), Ag85C (25 ng/ml), and a cocktail of all these antigens having the same concentration as described above was coated on a 96-well ELISA plate (flat bottom, Nunc Maxisorp, Roskilde, Denmark) in $0.05 \mathrm{M}$ carbonate bicarbonate buffer, $\mathrm{pH}$ 9.6. The working dilution of each antigen was standardized using checkerboard titration as described earlier (Kumar et al. 2008). After overnight incubation at $37^{\circ} \mathrm{C}$, the contents of all the wells were aspirated and the plate was washed three times with $150 \mathrm{mM}$ PBS, $\mathrm{pH}$ 7.4. The plate was blocked with $2 \%$ BSA (Sigma, St. Louis, MO, USA) in PBS $(200 \mu \mathrm{l} /$ well $)$ for $1 \mathrm{~h}$. After washing with PBST (with $0.05 \%$ Tween-20), serum diluted 1:200 in assay diluent (1\% BSA in PBS with $0.05 \%$ Tween-20) was added in duplicate wells and incubated at $37^{\circ} \mathrm{C}$ for $2 \mathrm{~h}$. Anti-human IgG peroxidaseconjugated antibody (Sigma, St. Louis, MO, USA) diluted 1:10,000 in assay diluent was added to each well. After incubation for $1 \mathrm{~h}, 100 \mu \mathrm{l}$ of substrate solution (orthophenylene diamine (OPD) tablet of $5 \mathrm{mg}$ dissolved in $10 \mathrm{ml}$ of distilled water and $50 \mu \mathrm{H}_{2} \mathrm{O}_{2}$ ) was added to each well and kept at room temperature for $20 \mathrm{~min}$ in the dark. The reaction was stopped by adding $50 \mu \mathrm{l}$ of $7 \% \mathrm{H}_{2} \mathrm{SO}_{4}$ (stop solution) to each well and the absorbance was measured at $492 \mathrm{nM}$ using a Spectramax-M2 Reader (Molecular Devices, Sunnyvale, CA, USA). All the experiments were carried out at least two times.

\section{Preparation of Whole-Cell Extracts}

The growth of M. tuberculosis culture was harvested at the late log phase (3 weeks) from Sauton's medium and washed twice with PBS $(150 \mathrm{mM}, \mathrm{pH} 7.4)$. Bacterial growth was then re-suspended $(0.2 \mathrm{~g}$ growth $/ \mathrm{ml})$ in lysis buffer (50 mM Tris, $10 \mathrm{mM} \mathrm{MgCl}_{2}, 1 \mathrm{mM}$ EGTA, $1 \mathrm{mM}$ PMSF, pH 7.4) and subjected to sub-cellular fractionation (Brodie et al. 1979) using a Vibra-Cell probe ultrasonicator for a total of $20 \mathrm{~min}$ using $50 \%$ output control $(100 \%=475 \mathrm{~W})$ and $50 \%$ duty cycle (on/off) at $4^{\circ} \mathrm{C}$. The extracts were then centrifuged at $23,000 \times g$ for $30 \mathrm{~min}$ to remove debris and the supernatant was collected. The protein concentration of each sample was determined using Bradford's method (Bradford 1976). These extracts were stored at $-20^{\circ} \mathrm{C}$ until used.

Immunoblot Analysis

Polyacrylamide gel electrophoresis (PAGE) was done under reducing conditions (Laemmli 1970) using 12\% (w/v) resolving gel in a Mini-Protean gel apparatus (Bio-Rad Laboratories, Hercules, CA, USA) by loading $20 \mu \mathrm{g} / \mathrm{lane}$ of protein extract. The molecular mass marker was obtained from Bio-Rad. The resolved proteins were transferred (Towbin et al. 1979) onto a nitrocellulose membrane $(0.45-\mu \mathrm{m}$ pore size; Sigma, St. Louis, MO, USA) using a TransBlot apparatus (Bio-Rad Laboratories, Hercules, CA, USA). The membrane was washed with PBS and blocked with $1 \%$ BSA (Sigma, St. Louis, MO, USA). The membrane was probed with sera diluted 1:400 in assay diluent (1\% BSA in PBS containing $0.05 \%$ Tween-20) overnight at $4^{\circ} \mathrm{C}$. The blots were washed with PBS containing $0.05 \%$ Tween-20 and incubated with anti-human IgG peroxidaseconjugated antibody (Sigma, St. Louis, MO, USA) diluted 1:5,000 in assay diluent for $1 \mathrm{~h}$. After final washing, the color was developed with diamino benzedine (Sigma, St. Louis, MO, USA) in citrate phosphate buffer $(0.5 \mathrm{M}$, pH $5)$. When reactivity was observed, the reaction was stopped by rinsing the membrane with distilled water. Data were analyzed by the Gel Documentation system (Bio-Rad Laboratories, Segrate (Milan), Italy) using Quantity One Software.

\section{Statistical Analysis}

Receiver operating characteristic (ROC) curves were constructed using Software Stata-7 (Strata Corporation, College Station, Texas, USA) to determine the cutoff, sensitivity, and specificity. Scattergrams were plotted using GraphPad prism software version 3.02 (San Diego, CA, USA).

\section{Results}

The focus of the present study was to identify the serodiagnostic potential of various secretory antigens of 
M. tuberculosis (ESAT-6, CFP-10, Ag85 complex as well as its individual components (A, B, C), and a cocktail of all these antigens) using ELISA. The antibody response to each antigen was analyzed in 76 well-characterized patients with active pulmonary TB (48 fresh TB, 20 defaulters, 8 relapsed TB), 10 extra-pulmonary TB, 10 partially/fully treated smear-negative cases of TB, 29 healthy controls, and 18 leprosy controls. Furthermore, the reactivity of sera against clinical isolates of $M$. tuberculosis was also evaluated by immunoblotting.

Sensitivity and specificity for a particular antigen were determined using ROC analysis. For all the antigens, the same numbers of TB cases, healthy individuals, and leprosy patients were taken. The cutoff was selected at the point which showed the best accuracy (correctly classifying individuals to their groups), sensitivity, and specificity by ROC. A predictive value (PV) to define the probability of a disease is very important as it provides the significance of a disease to characterize a patient for the particular disease from the patient's population $(+\mathrm{PV})$, and a high $-\mathrm{PV}$ is also needed to exclude the disease (Table 2); hence these parameters were also analyzed. Furthermore, concordance of IgG response to antigens that show good results in terms of sensitivity, specificity, and accuracy was determined to assess the chance of agreement (Table 3).

Antibody Response of Different Groups of TB Patients and Controls to the Various Secretory Antigens

We observed antibody reactivity of $64.9 \%$ and specificity of $88.9 \%$ for ESAT- 6 using the cutoff determined by ROC (Table 2). Positivity at this cutoff was $68.8 \%$ for fresh TB, $70 \%$ for defaulters, $62.5 \%$ for relapse, and $70 \%$ for extra- pulmonary TB. None of the leprosy patients were positive for this antigen, whereas only $30 \%$ of the treated TB cases were found to be positive for it (Fig. 1).

We noted slightly increased reactivity to CFP-10 antigen in comparison with ESAT-6 when sera from fresh TB $(72.8 \%)$, relapse cases $(75 \%)$, and treated cases $(40 \%)$ were measured. But this antigen was less reactive $(55 \%)$ with the sera of defaulter cases of TB. Reactivity of extra-pulmonary TB was found to be similar (70\%) to that of ESAT-6. We did not note any reactivity of the sera of leprosy patients to this antigen (Fig. 1). The overall sensitivity to this antigen was $66.0 \%$ and specificity $85.2 \%$ (Table 2).

The reactivity for Ag85 complex was the highest $(84.1 \%)$ of all the antigens used in this study, with a specificity of $85.2 \%$ (Table 2). We observed $88.9 \%$ reactivity in the fresh TB group, $90 \%$ in defaulters, $75 \%$ in relapse cases, $80 \%$ in extra-pulmonary TB, $60 \%$ in treated cases of $\mathrm{TB}$, and $6.89 \%$ in leprosy patients to this antigen (Fig. 1).

The reactivities to the individual components $\mathrm{Ag} 85 \mathrm{~A}$, $\mathrm{Ag} 85 \mathrm{~B}$, and $\mathrm{Ag} 85 \mathrm{C}$ of $\mathrm{Ag} 85$ complex were 44.6, 34.0, and $80.9 \%$ and specificity $55.6,74.1$, and $40.7 \%$, respectively (Table 2). Furthermore, 36.6, 35.4, and $93.7 \%$ of fresh TB cases were reactive to the $\mathrm{Ag} 85 \mathrm{~A}, \mathrm{~B}$, and $\mathrm{C}$ components respectively. The observed reactivities of sera from the defaulter cases were 55,45 , and $80 \%$, respectively. We noted $62.5 \%$ reactivity with $\mathrm{Ag} 85 \mathrm{~A}, 62.5 \%$ with $\mathrm{Ag} 85 \mathrm{~B}$, and $87.5 \%$ with $\mathrm{Ag} 85 \mathrm{C}$ in the sera of relapse cases. None of the extra-pulmonary TB cases showed antibody response to $\mathrm{Ag} 85 \mathrm{~A}$ or $\mathrm{Ag} 85 \mathrm{~B}$, although $30 \%$ reactivity was noted using $\mathrm{Ag} 85 \mathrm{C}$. The leprosy controls reacted more (44.4\%) with the Ag85C component than to Ag85A (33.3\%) and Ag85B (5.5\%). Reactivities in the treated TB cases were

Table 2 Immunoglobulin G reactivity against various secretory antigens of M. tuberculosis at cut off decided by ROC analysis

\begin{tabular}{|c|c|c|c|c|c|c|c|c|}
\hline Antigen & Cutoff & Sensitivity (\%) & Specificity (\%) & $+\mathrm{PV}(\%)$ & $-\mathrm{PV}(\%)$ & $+\mathrm{LR}$ & $-\mathrm{LR}$ & $\mathrm{ROC}$ area \\
\hline ESAT-6 & 0.331 & 64.9 & 88.9 & 95.3 & 42.1 & 5.84 & 0.39 & 0.743 \\
\hline CFP-10 & 0.293 & 66.0 & 85.2 & 93.9 & 41.8 & 4.45 & 0.40 & 0.746 \\
\hline Ag85 complex & 0.150 & 84.1 & 85.2 & 95.2 & 60.5 & 5.67 & 0.19 & 0.879 \\
\hline Ag85A & 0.119 & 44.6 & 55.6 & 77.4 & 23.2 & 1.01 & 0.10 & 0.496 \\
\hline $\mathrm{Ag} 85 \mathrm{~B}$ & 0.163 & 34.0 & 74.1 & 82.8 & 24.4 & 1.31 & 0.89 & 0.545 \\
\hline $\mathrm{Ag} 85 \mathrm{C}$ & 0.072 & 80.9 & 40.7 & 82.6 & 37.9 & 1.36 & 0.47 & 0.603 \\
\hline Cocktail & 0.114 & 51.1 & 85.2 & 92.3 & 33.3 & 3.45 & 0.57 & 0.685 \\
\hline
\end{tabular}

Table 3 Correlation of antibody reactivity of various secretory antigens

\begin{tabular}{llllllll}
\hline $\begin{array}{l}\text { ESAT-6-CFP- } \\
\begin{array}{l}\text { 10+/Total } \\
\text { patients }\end{array}\end{array}$ & $\begin{array}{l}\text { CFP-10-ESAT- } \\
\text { 6+/Total } \\
\text { patients }\end{array}$ & $\begin{array}{l}\text { Ag85-ESAT- } \\
\text { 6+/Total } \\
\text { patients }\end{array}$ & $\begin{array}{l}\text { Ag85-CFP- } \\
\text { 10+/Total } \\
\text { patients }\end{array}$ & $\begin{array}{l}\text { Ag85- } \\
\text { Ag85A+/Total } \\
\text { patients }\end{array}$ & $\begin{array}{l}\text { Ag85- } \\
\text { Ag85B+/Total } \\
\text { patients }\end{array}$ & $\begin{array}{l}\text { Ag85- } \\
\text { Ag85C+/Total } \\
\text { patients }\end{array}$ & $\begin{array}{l}\text { Ag85- } \\
\text { Cocktail+/Total } \\
\text { patients }\end{array}$ \\
\hline $7 / 76$ & $7 / 76$ & $1 / 76$ & Nil/76 & $5 / 76$ & $4 / 76$ & $7 / 76$ & $4 / 76$ \\
\hline
\end{tabular}


Fig. 1 Antibody reactivity to various secretory antigens of M. tuberculosis with sera derived from different clinical groups (FTB: fresh untreated, $D T B$ : defaulters, $R T B$ : relapsed, $E P T B$ : extra-pulmonary TB) of tuberculosis patients and controls (HC: healthy controls, $L P$ : leprosy patients). $T t T B$ denotes the treated cases of tuberculosis. Each scatter represents a tested sample of serum, the dotted line denotes the cutoff decided by ROC

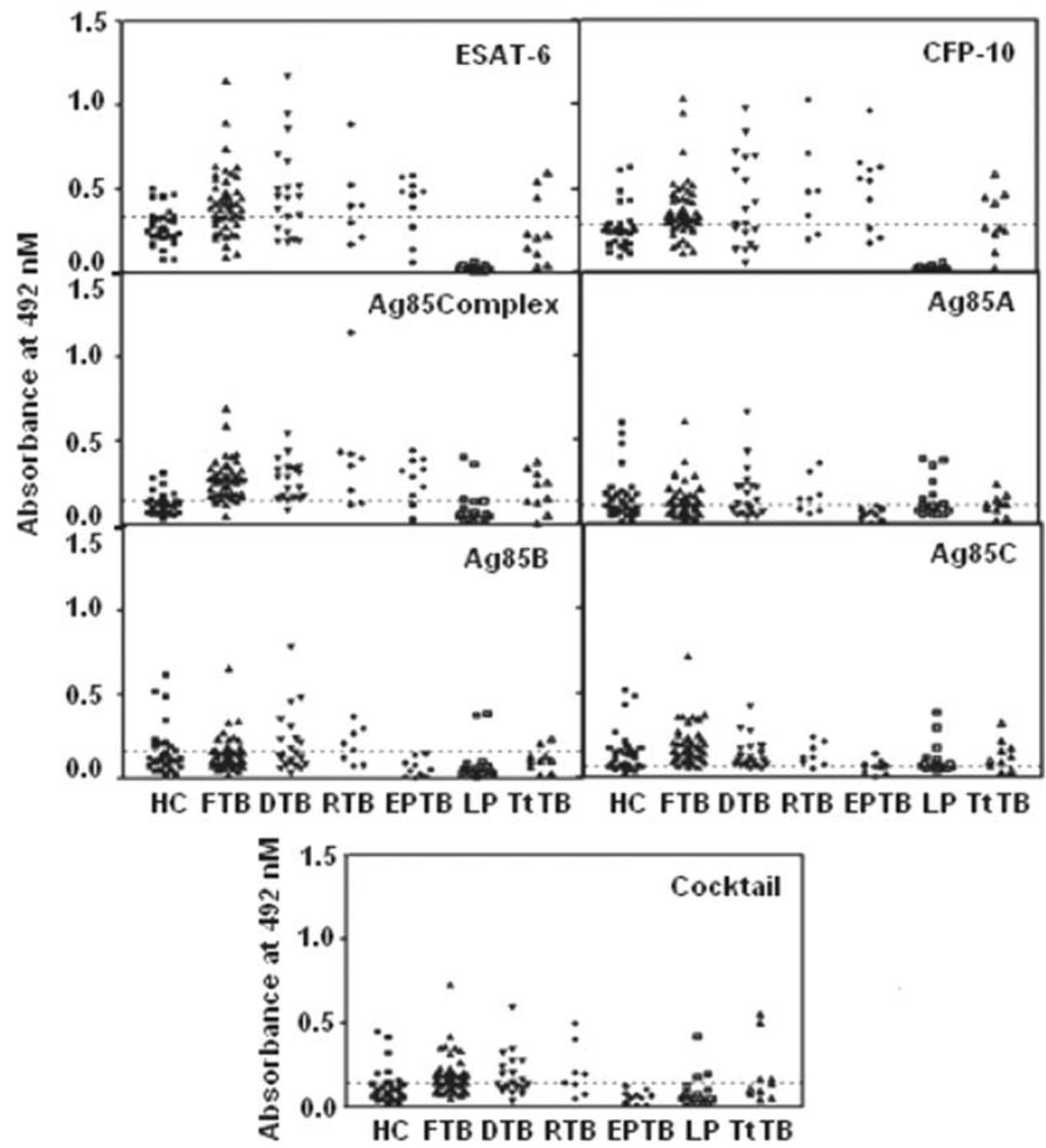

only 40, 20, and 70\% for Ag85A, Ag85B, and Ag85C, respectively (Fig. 1).

We observed lower reactivity $(51.1 \%)$ using the cocktail of all these antigens, but the specificity was the same (85.2\%) as that reported for the Ag85 complex (85.2\%) (Table 2). However, antibody reactivity in fresh, relapse, and defaulter TB cases, treated cases of TB, and leprosy cases was observed to be $64.6,75,50,40$, and $16.6 \%$, respectively. No reactivity was noted with this antigen in the extra-pulmonary TB patients (Fig. 1). Interestingly, four of the healthy individuals were reactive to all the antigens used in this study.

Correlation of Reactivity of Individual Patients

to Various Secretory Antigens

The antibody responses to the various secretory antigens were also correlated. We noted antibody response to ESAT-6 in seven patients who did not show antibody to CFP-10 and, similarly, antibody reactivity to CFP-10 was noted in seven patients who were negative for ESAT-6. All the patients negative for Ag85 complex were also negative for CFP-10 and ESAT-6, except one patient who was positive for ESAT-6. However, five patients who showed antibody reactivity to Ag85A were not positive for Ag85 complex, and 4 patients who were negative for Ag85 complex were positive for both Ag85B and the cocktail. Using Ag85C, we were able to detect seven more positive patients who were negative for Ag85 complex (Table 3). Furthermore, the areas under the ROC curves were compared for all these antigens (Table 2 and Fig. 2); it was highest for Ag85 complex (0.879), followed by CFP-10 (0.746) and ESAT-6 (0.743).

Sero-reactivity of Ag85 Complex, ESAT-6, and CFP-10 by Employing Western Blotting with H37Rv and Clinical Isolates of M. tuberculosis

We further analyzed the antibody reactivity to 39 clinical isolates from different regions of India using the pooled 


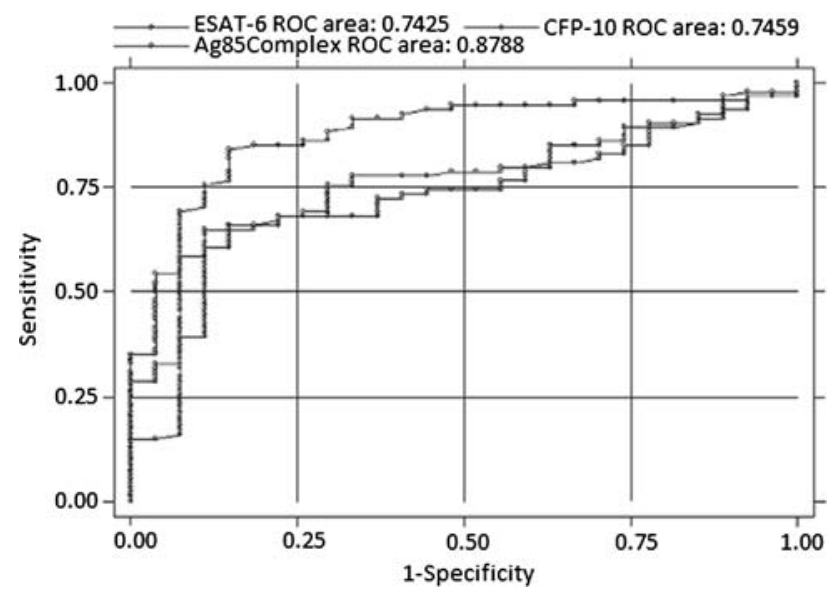

Fig. 2 Area under ROC of three significant antigens with sera from tuberculosis patients

sera from fresh TB patients. Reactivity to the Ag85 complex was observed in almost all the isolates as well as in H37Rv (data not shown). Finally, five clinical isolates were randomly selected from all these clinical isolates, taking their reactivity and growth profile into consideration. Using these isolates, the seroreactivities of the individual sera were evaluated (Fig. 3).

Significant reactivity at the $30-\mathrm{kDa}$ region $(\mathrm{Ag} 85$ complex) in $\mathrm{H} 37 \mathrm{Rv}$ as well as in all five clinical isolates was observed in both the TB patients used in the study (Fig. 3c, d) compared with two BCG-vaccinated individuals (Fig. 3a, b). However, only one patient was reactive to the 6-kDa region (ESAT-6) in 4 clinical isolates and to the $10-\mathrm{kDa}$ region (CFP-10) in 3 isolates, but the reactivity was low (Fig. 3c, d). Interestingly, one person with contact with TB exhibited reactivity to the 30$\mathrm{kDa}$ region (Ag85 complex) in $\mathrm{H} 37 \mathrm{Rv}$ and in 2 clinical isolates and to the 6-kDa region (ESAT-6) in two clinical isolates (Fig. 3e). The reactivity to Ag85 complex in the clinical isolates was observed to be slightly greater than that in $\mathrm{H} 37 \mathrm{Rv}$ when all these strains were hybridized with antibody against Ag85 complex (Fig. 3h). Reactivity to ESAT-6 and CFP-10 in the clinical isolates was shown after treating the transferred proteins with anti-ESAT-6 and -CFP-10 antibody (Fig. 3g).

\section{Discussion}

The management of tuberculosis in the regions of developing countries urgently needs an efficient diagnostic test that should be simple to perform with limited cost. Extensive studies have been done using various antigens of M. tuberculosis (Abebe et al. 2007; Mishra et al. 2008). The antigens selected for the current study have been reported to be strong targets for humoral and cell-mediated immune response (Barnes 2004; Kanaujia et al. 2003; Kanaujia et al. 2004; Mori et al. 2004; Samanich et al. 2001; Van Vooren et al. 1992).

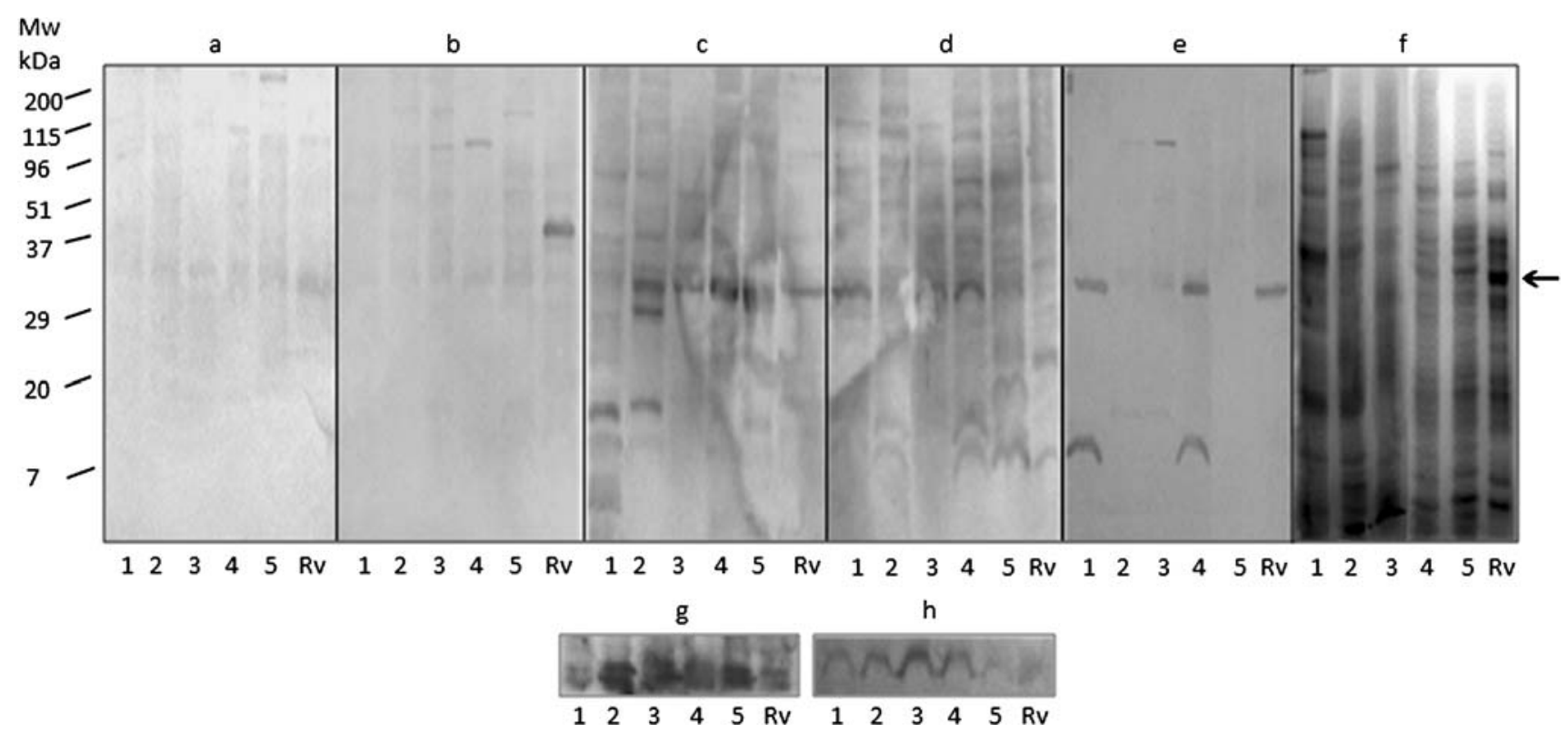

Fig. 3 Lanes 1-5 of whole-cell extracts (WCEs) of clinical isolates of $M$. tuberculosis. a, b Blotting with BCG-vaccinated healthy individual's sera. c-d Reactivity with individual tuberculosis patient's sera. e Reactivity pattern of contact with tuberculosis. f $12 \%$ SDSPAGE gel pattern of WCEs of clinical isolates and H37Rv. g Hybridization of polyclonal antibody against ESAT-6 and CFP-10 with whole-cell extracts. h Hybridization of monoclonal antibody (CS-90) against Ag85 complex with WCEs of clinical isolates and H37Rv. Rv: M. tuberculosis laboratory reference strain H37Rv; arrow shows the reactivity pattern of $\mathrm{Ag} 85$ complex 
Studies using ESAT-6 suggested its role as a marker of risk (Davidow et al. 2005; Silva et al. 2003) and progressive TB (Demissie et al. 2006). Berthet et al. reported a highly specific antigen present in the RD1 region, and CFP10 is found in the same strongly stimulatory fraction of culture filtrate as ESAT-6, with limited distribution outside the TB complex (Berthet et al. 1998). In our study, very little difference between ESAT-6 (64.9\%) and CFP-10 $(66.0 \%)$ reactivity was observed. This finding was in support of a study in which some relatedness between ESAT-6 and CFP-10 at the amino-acid level was reported (Skjot et al. 2000). Interaction between ESAT-6 and CFP-10 genes and the co-transcription of these antigens were also demonstrated (Berthet et al. 1998). However, in our study, antibody to ESAT-6 was observed in seven TB patients but not to CFP-10 and vice versa (Table 3 ). This finding suggests a sequence difference between CFP-10 and ESAT-6.

India is a known endemic country for tuberculosis and leprosy and a study documented the presence of orthologues of ESAT-6 and CFP-10 in other mycobacteria, including M. leprae (Gey Van Pittius et al. 2001). Therefore, control sera from leprosy patients were also included in the present study to determine the cross-reactivity of antigens in leprosy and tuberculosis. To our surprise, none of the leprosy patients were found to have antibody response against either ESAT-6 or CFP-10. We noted reactivity in healthy individuals, due to which a higher cutoff was chosen for these two antigens, which could be one of the reasons for the low positivity among the leprosy patients. Genes of these proteins are reported to be present in other pathogenic mycobacteria, for example $M$. africanum, M. kansasii, M. marinum, M. szulgai (Harboe et al. 1996; Sorensen et al. 1995), and M. bovis (Harboe et al. 1996), as well as the slow-growing nonpathogenic mycobacterium M. gastri (Colangeli et al. 2000) and the fastgrowing nonpathogenic environmental species $M$. flavesens (Harboe et al. 1996). All the healthy individuals were either staff or students working at our institute, hence higher reactivity to ESAT-6 could be due to the presence of crossreactive antibodies to these mycobacteria. In our previous study we noted overall sensitivity and specificity of 53.01 and $91 \%$, respectively, for ESAT-6 in pediatric TB patients (Dayal et al. 2006).

Although Ag85 complex is reported to be cross-reactive with other mycobacteria as well (Rinke de Wit et al. 1993), we observed the highest sensitivity (84.0\%) and $85.2 \%$ specificity (Table 1) using Ag85 complex. In an earlier report, Ag85 complex was reported to be $72 \%$ sensitive and $100 \%$ specific in Mexican Totonac Indians with pulmonary tuberculosis (Sanchez-Rodriguez et al. 2002). Similar findings have been confirmed by others (Abdelnour et al. 2000). Furthermore, we observed high antibody (60\%) against Ag85 complex in patients undergoing anti-TB treatment, which suggests persistence of this antigen for longer duration. A recent report also indicates the immuno-dominant nature of Ag85 complex (Malen et al. 2008).

The seroreactivity of Ag85A in our study was $44.68 \%$ in TB patients and it was only $55.66 \%$ specific. This antigen was also noted to be highly reactive with the sera of leprosy patients (33.33\%). Antibody reactivity to Ag85B was only $33.0 \%$ and specificity $74.1 \%$ (Table 2). Antibody response to different components of the Ag85 complex was also reported earlier (Lim et al. 1999; Samanich et al. 2000; Van Vooren et al. 1992). Van Vooren et al. suggested that Ag85B was the most useful component of the Ag85 complex for the serodiagnosis of the active form of TB (Van Vooren et al. 1991). This was further supported by Lim et al., who showed that the antibody responses to $\mathrm{Ag} 85 \mathrm{~B}$ and $\mathrm{Ag} 85 \mathrm{~A}$ in patients were significantly greater than those to the Ag85C protein (Lim et al. 1999). Ag85B (Rv1886c) was reported to be 41-94\% sensitive in various studies (Raja et al. 2002, 2005; Steingart et al. 2009; Uma Devi et al. 2003; Vikerfors et al. 1993). In contrast, McDonough et al. failed to detect antibodies against Ag85B (McDonough et al. 1992). We noted antibody to Ag85B in four more patients compared with the Ag85 complex (Table 2). However, antibodies to Ag85A and Ag85B have been reported to appear in extensive disease state (Sada et al. 1990). Ag85C has also been identified as an early marker for TB diagnosis; reactivity to this antigen has been reported in $36 \%$ of patients and it was reported to be $100 \%$ specific in HIVpositive smear-positive cases of TB (Samanich et al. 2000). We noted sensitivity of $80.9 \%$ and specificity of only $40.7 \%$ using this antigen. In contrast, Samanich et al., in their study on HIV-negative smear-positive TB patients, showed $80 \%$ reactivity to this antigen (Samanich et al. 2000). In our study, Ag85C was found to be highly reactive in leprosy patients $(44.4 \%)$ among all the antigens. In a very recent study we reported strong reactivity with high specificity to Ag85C in pediatric TB patients (Kumar et al. 2008), which could be possible because of less exposure of pediatric patients to environmental mycobacteria. Homologues of Ag85 complex are also present in nonpathogenic mycobacteria (Rinke de Wit et al. 1993) and, this being an endemic country, it is possible that the controls taken for our study were already exposed and had antibody to these antigens. Despite the presence of cross-reactive epitope sequences, the stronger reactivity of the sera from $\mathrm{TB}$ patients to Ag85 complex suggests that this antigen also has some specific immunodominant sequences for the diagnosis of TB.

Further in our study, the antibody reactivity of two patients to all the clinical isolates is suggestive of similar expression of Ag85 complex genes and a relative 
immuno-dominant nature of this antigen complex. Reactivity to ESAT-6 in H37Rv and four clinical isolates was observed in one TB patient. Furthermore, a blot with a contact of TB also showed strong reactivity against Ag85 complex in H37Rv as well as two clinical isolates and with ESAT-6 in two clinical isolates (out of 5) (Fig. 3e). These results highlight the importance of Ag85 complex and ESAT-6 in minimizing the heterogeneous immune response of TB patients (Fig. 3c, d). Although the reactivity was analyzed with only one contact of $\mathrm{TB}$, this finding indicates that exposure status could be identified using Ag85 complex and ESAT-6. Furthermore, studies taking more contacts of tuberculosis would be helpful for a strong conclusion. However, the reactivity with CFP-10 was low.

Several reports indicate that the pattern of antigen reactivity to various antibodies in serum varied greatly from patient to patient and no antigen alone can perform significantly for the diagnosis of TB (Abebe et al. 2007; Lyashchenko et al. 1998). Therefore, a cocktail of these antigens was made to minimize the possible heterogeneity of antigen recognition by patients. The lower sensitivity reported for the cocktail in the present study might be due to steric hindrance or masking of some of the dominant epitopes in the cocktail, as observed in our previous study of pediatric patients with TB (Kumar et al. 2008).

This is the first report from northern India to show a response to highly specific (ESAT-6, CFP-10) and immuno-dominant antigen 85 in complex form as well as its individual components in adult patients with tuberculosis. The strong antibody responses against Ag85 complex (despite the presence of cross-reacting epitopes in BCG and other non-tuberculous mycobacteria), ESAT-6, and CFP-10 in all the categories of active TB suggest the potential of these antigens. These antigens could be more useful in a high-prevalence area of TB to develop an array for serodiagnosis. Therefore, detailed epitope-based studies of these secretory antigens might be promising to provide specific sequences for the serodiagnosis of TB. Collectively, these results also indicate that an array of antigens would be more useful for developing a simple and inexpensive serodiagnostic test for the diagnosis of adult cases of tuberculosis than a mixture of various antigens.

Acknowledgments We are grateful to Dr. John T. Belisle, Colorado State University, (Colorado, USA) for providing the recombinant and native antigens of $M$. tuberculosis used in the present study. We thank Dr. B. K. Girdhar, NJIL \& OMD, Agra, for providing well-diagnosed serum samples of leprosy patients, Ms Rajni Upadhyay and Ms Bhavyata Dua, NJIL \& OMD, for their help in preparing this manuscript. The authors acknowledge ICMR and DBT, New Delhi, for financial support and UGC-CSIR and ICMR, New Delhi, for providing fellowships to GK and PKD, respectively. Help given by Mr. M. M. Alam, Lab Technician, Immunology Department, NJIL \& OMD, Agra, for sample collection and Mr. Navneet Kulshreshtha,
Lab Technician, Microbiology \& Molecular Biology Department, NJIL \& OMD, for mycobacterial culture is also acknowledged.

\section{References}

Abdelnour AM, Khaled G, Matar GM et al (2000) Evaluation of a serological test for the diagnosis of tuberculosis using the $38 \mathrm{kDa}$ antigen. East J Medi 5:10-12

Abebe F, Holm-Hansen C, Wiker HG et al (2007) Progress in serodiagnosis of Mycobacterium tuberculosis infection. Scan J Immunol 66:176-191

American Thoracic Society (2000) Diagnostic standards and classification of tuberculosis in adults and children. Am J Respir Crit Care Med 161:1376-1395

Arend SM, Andersen P, van Meijgaarden KE et al (2000) Detection of active tuberculosis infection by $\mathrm{T}$ cell responses to early secreted antigen target $6 \mathrm{kDa}$ protein and culture filtrate protein 10 . J Infect Dis 181:1850-1854

Barnes PF (2004) Diagnosing latent tuberculosis infection, turning glitter to gold. Am J Respir Crit Care Med 170:5-6

Berthet FX, Rasmussen PB, Rosenkrands I et al (1998) A Mycobacterium tuberculosis operon encoding ESAT-6 and a novel lowmolecular-mass culture filtrate protein (CFP-10). Microbiology 144:3195-3203

Bradford MM (1976) A rapid and sensitive method for the quantitation of microgram quantities of protein utilizing the principle of protein-dye binding. Anal Biochem 72:248-254

Brodie AF, Kalra VK, Lee SH et al (1979) Properties of energytransducing systems in different types of membrane preparations from Mycobacterium phlei-preparation, resolution, and reconstitution. Methods Enzymol 55:175-199

Colangeli R, Spencer JS, Bifani P et al (2000) MTSA-10, the product of the Rv3874 gene of Mycobacterium tuberculosis, elicits tuberculosis-specific, delayed-type hypersensitivity in guinea pigs. Infect Immun 68:990-993

Davidow A, Kanaujia GV, Shi L et al (2005) Antibody profiles characteristic of M. tuberculosis infection state. Infect Immun 73:6846-6851

Dayal R, Sirohi G, Singh MK et al (2006) Diagnostic value of ELISA serological tests in childhood tuberculosis. J Trop Pediatr 52:433-437

Demissie A, Leyten EM, Abebe M et al (2006) Recognition of stagespecific mycobacterial antigens differentiates between acute and latent infections with Mycobacterium tuberculosis. Clin Vaccine Immunol 13:179-186

Fine PE, Bruce J, Ponnighaus JM et al (1999) Tuberculin sensitivity: conversions and reversions in a rural African population. Int $\mathrm{J}$ Tuberc Lung Dis 3:962-975

Gey Van Pittius NC, Gamieldien J, Hide W et al (2001) The ESAT-6 gene cluster of Mycobacterium tuberculosis and other high G + C Gram-positive bacteria. Genome Biol 2:research0044.10044.18

Harboe M, Oettinger T, Wiker HG et al (1996) Evidence for occurrence of the ESAT-6 protein in Mycobacterium tuberculosis and virulent Mycobacterium bovis and for its absence in Mycobacterium bovis BCG. Infect Immun 64:16-22

Hawkinds JE et al (1991) Antibacterial susceptibility tests. In: Manual of clinical microbiology, 5 edn. American Society for Microbiology, Washington DC, pp 1138-1152

Huebner RE, Schein MF, Bass JB Jr (1993) The tuberculin skin test. Clin Infect Dis 17:968-975

Kanaujia GV, Garcia MA, Bouley DM et al (2003) Detection of early secretory antigenic target- 6 antibody for diagnosis of tuberculosis in non-human primates. Comp Med 53:602-606 
Kanaujia GV, Motzel S, Garcia MA et al (2004) Recognition of ESAT-6 sequences by antibody in sera of tuberculosis nonhuman primates. Clin Diag Lab Immunol 11:222-226

Kumar G, Dagur PK, Singh M et al (2008) Diagnostic potential of $\mathrm{Ag} 85 \mathrm{C}$ in comparison to various secretory antigens for childhood tuberculosis. Scand J Immunol 68:177-183

Laemmli UK (1970) Cleavage of structural proteins during the assembly of the head of bacteriophage T4. Nature 227:680-685

Lim JH, Park JK, Jo EK et al (1999) Purification and immunoreactivity of three components from the 30/32-kilodalton antigen 85 complex in Mycobacterium tuberculosis. Infect Immun 67:61876190

Lyashchenko K, Colangeli R, Houde M et al (1998) Heterogeneous antibody responses in tuberculosis. Infect Immun 66:3936-3940

Malen H, Softeland T, Wiker HG (2008) Antigen analysis of Mycobacterium tuberculosis $\mathrm{H} 37 \mathrm{Rv}$ culture filtrate proteins. Scan J Immunol 67:245-252

McDonough JA, Sada DE, Sippola AA et al (1992) Microplate and dot immunoassays for the serodiagnosis of tuberculosis. J Lab Clin Med 120:318-322

Mishra KC, de Chastellier C, Narayana Y et al (2008) Functional role of the PE domain and immunogenicity of the Mycobacterium tuberculosis triacylglycerol hydrolase LipY. Infect Immun 76:127-140

Mori T, Sakatani M, Yamagishi F et al (2004) Specific detection of tuberculosis infection: an interferon-gamma-based assay using new antigens. Am J Respir Crit Care Med 170:59-64

Noordhoek GT, Kolk AH, Bjune G et al (1994) Sensitivity and specificity of polymerase chain reaction for detection of $M$. tuberculosis, a blind comparison study among seven laboratories. J Clin Microbiol 32:277-284

Raja A, Uma Devi KR, Ramalingam B et al (2002) Immunoglobulin $\mathrm{G}, \mathrm{A}$, and $\mathrm{M}$ responses in serum and circulating immune complexes elicited by the 16-kilodalton antigen of Mycobacterium tuberculosis. Clin Diagn Lab Immunol 9:308-312

Raja A, Uma Devi KR, Ramalingam B et al (2005) Improved diagnosis of pulmonary tuberculosis by detection of free and immune complex-bound anti-30 kDa antibodies. Diagn Microbiol Infect Dis 50:253-259

Rinke de Wit TF, Bekelie S, Osland A et al (1993) The Mycobacterium leprae antigen 85 complex gene family: identification of the gene for the $85 \mathrm{~A}, 85 \mathrm{C}$, and related MPT51 proteins. Infect Immun 61:3642-3647

Sada E, Ferguson LE, Daniel TM (1990) An ELISA for the serodiagnosis of tuberculosis using a 30,000-Da native antigen of Mycobacterium tuberculosis. J Infect Dis 162:928-931

Samanich KM, Keen MA, Vissa VD et al (2000) Serodiagnostic potential of culture filtrate antigens of Mycobacterium tuberculosis. Clin Diagn Lab Immunol 7:662-668

Samanich K, Belisle JT, Laal S (2001) Homogeneity of antibody responses in tuberculous patients. Infect Immun 69:4600-4609
Sanchez-Rodriguez C, Estrada-Chavez C, Garcia-Vigil J et al (2002) An IgG antibody response to the antigen 85 complex is associated with good outcome in Mexican Totonaca Indians with pulmonary tuberculosis. Int J Tuberc Lung Dis 6:706-712

Silva VM, Kanaujia G, Gennaro ML et al (2003) Factors associated with humoral response to ESAT-6, $38 \mathrm{kDa}$ and $14 \mathrm{kDa}$ in patients with a spectrum of tuberculosis. Int $\mathbf{J}$ Tuberc Lung Dis 7:478-484

Skjot RLV, Oettinger T, Rosenkrands I et al (2000) Comparative evaluation of low-molecular-mass proteins from Mycobacterium tuberculosis identifies members of the ESAT-6 family as immunodominant T-cell antigens. Infect Immun 68:214-220

Sorensen AL, Nagai S, Houen G et al (1995) Purification and characterization of a low-molecular-mass T-cell antigen secreted by Mycobacterium tuberculosis. Infect Immun 63:1710-1717

Steingart KR, Dendukuri N, Henry M et al (2009) Performance of purified antigens for serodiagnosis of pulmonary tuberculosis: a meta-analysis. Clin Vaccine Immunol 16:260-276

Thornton CG, MacLellan KM, Brink TL Jr et al (1998) In vitro comparison of NALC-NaOH, tween 80, and C18-carboxypropylbetaine for processing of specimens for recovery of mycobacteria. J Clin Microbiol 36:3558-3566

Towbin H, Staehelin T, Gordon J (1979) Electrophoretic transfer of proteins from polyacrylamide gels to nitrocellulose sheets: procedure and some applications. Proc Natl Acad Sci USA 76:4350-4354

Uma Devi KR, Ramalingam B, Raja A (2003) Antibody response to Mycobacterium tuberculosis 30 and $16 \mathrm{kDa}$ antigens in pulmonary tuberculosis with human immunodeficiency virus coinfection. Diagn Microbiol Infect Dis 46:205-209

Van Vooren JP, Drowart A, De Cock M et al (1991) Humoral immune response of tuberculous patients against the three components of the Mycobacterium bovis BCG 85 complex separated by isoelectric focusing. J Clin Microbiol 29:2348-2350

Van Vooren JP, Drowart A, De Bruyn J et al (1992) Humoral responses against the 85A and 85B antigens of Mycobacterium bovis $\mathrm{BCG}$ in patients with leprosy and tuberculosis. J Clin Microbiol 30:1608-1610

Vikerfors T, Olcen P, Wiker H et al (1993) Serological response in leprosy and tuberculosis patients to the $18-\mathrm{kDa}$ antigen of Mycobacterium leprae and antigen 85B of Mycobacterium bovis BCG. Int J Lepr Other Mycobact Dis 61:571-580

Wiker HG, Harboe M (1992) The antigen 85 complex, a major secretion product of Mycobacterium tuberculosis. Microbiol Rev 56:648-661

Wiker HG, Harboe M, Nagai S et al (1986) MPB59, a widely crossreacting protein of Mycobacterium bovis BCG. Int Arch Allergy Appl Immunol 81:307-314

World Health Organization, WHO Report (2007) Global tuberculosis control, surveillance, planning, financing. WHO, Geneva, $277 \mathrm{pp}$ 